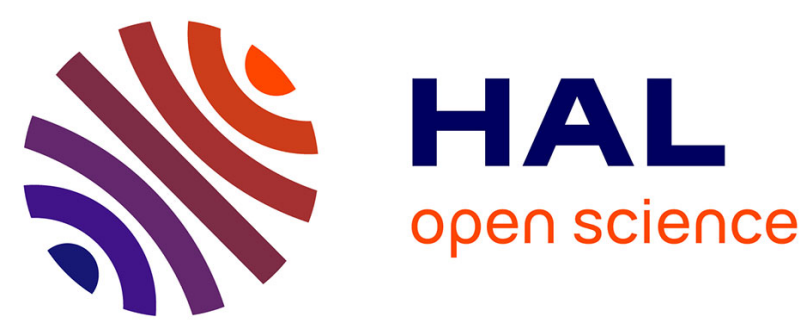

\title{
Catalytically active peptides affected by self-assembly and residues order
}

\author{
Avigail Baruch-Leshem, Corinne Chevallard, Frédéric Gobeaux, Patrick \\ Guenoun, Jean Daillant, Philippe Fontaine, Michel Goldmann, Ariel \\ Kushmaro, Hanna Rapaport
}

\section{To cite this version:}

Avigail Baruch-Leshem, Corinne Chevallard, Frédéric Gobeaux, Patrick Guenoun, Jean Daillant, et al.. Catalytically active peptides affected by self-assembly and residues order. Colloids and Surfaces

B: Biointerfaces, 2021, 203, pp.111751. 10.1016/j.colsurfb.2021.111751 . cea-03198649

\section{HAL Id: cea-03198649 \\ https://hal-cea.archives-ouvertes.fr/cea-03198649}

Submitted on 15 Apr 2021

HAL is a multi-disciplinary open access archive for the deposit and dissemination of scientific research documents, whether they are published or not. The documents may come from teaching and research institutions in France or abroad, or from public or private research centers.
L'archive ouverte pluridisciplinaire HAL, est destinée au dépôt et à la diffusion de documents scientifiques de niveau recherche, publiés ou non, émanant des établissements d'enseignement et de recherche français ou étrangers, des laboratoires publics ou privés. 


\section{Catalytically Active Peptides Affected by Self-Assembly and Residues Order}

Avigail Baruch-Leshem ${ }^{\mathrm{a}}$, Corinne Chevallard ${ }^{\mathrm{b}}$, Frederic Gobeaux ${ }^{\mathrm{b}}$, Patrick Guenoun ${ }^{\mathrm{b}}$, Jean Daillant $^{c}$, Philippe Fontaine ${ }^{c, d}$, Michel Goldmann ${ }^{c, d, e}$, Ariel Kushmaro ${ }^{f}$ and Hanna Rapaport ${ }^{* f}$ hannarap@bgu.ac.il

a. Unit of Environmental Engineering Ben-Gurion University of the Negev POB 653, Beer-Sheva, 8410501 Israel

b. Université Paris-Saclay, CEA, CNRS, NIMBE, LIONS, 91191, Gif-sur-Yvette, France.

c. Synchrotron SOLEIL, L’Orme des Merisiers, Saint-Aubin BP48, 91192 Gif-Sur-Yvette, France

d. Sorbonne Universités, UPMC, Institut des NanoSciences de Paris, CNRS-UMR 7588, 4 place Jussieu, 75005 Paris, France

e. Faculté des Sciences Fondamentales et Biomédicales, Université de Paris, 45 rue des Saints Pères, 75006 Paris, France

f. Avram and Stella Goldstein-Goren Department of Biotechnology Engineering and Ilse Katz Institute for Nanoscience and Technology, Ben-Gurion University of the Negev POB 653, Beer-Sheva, 8410501 Israel

Graphical abstract

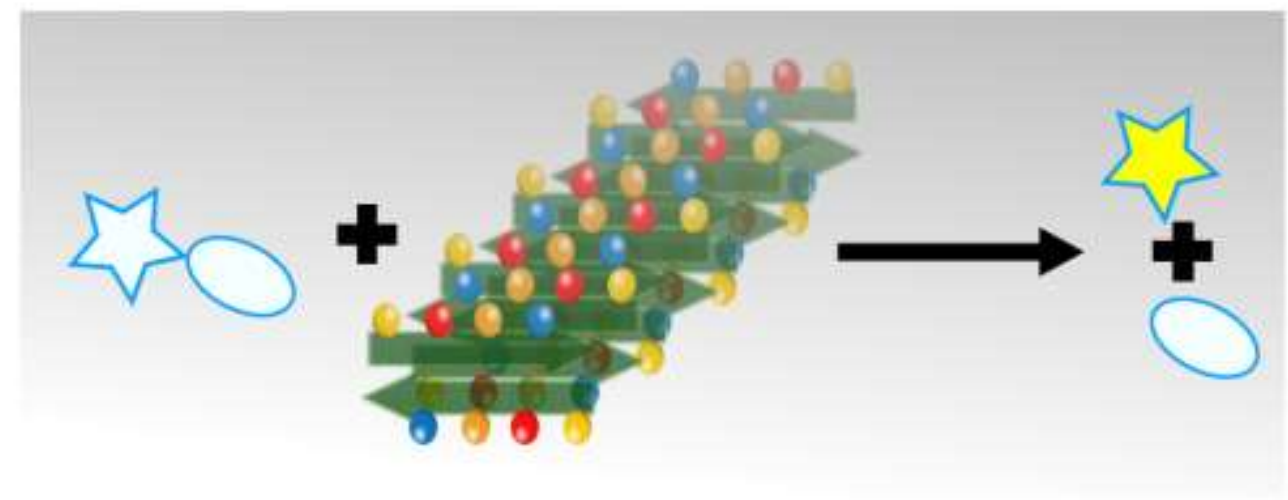

Highlights

- Designed peptides showed a link between catalytic amino acids order and activity 
- Side chains engaged in stabilizing order may become inaccessible to catalysis

- Structural characterizations do provide insights on catalysis by peptide assemblies

\section{Abstract}

Amphiphilic peptides that induce catalysis are interesting alternatives to natural enzymes thanks to robustness of their synthesis and the ability to induce certain types of conformations by specific motifs of amino acid sequences. Various studies aimed at mimicking the activity of serine proteases by designed peptides. Here we demonstrate that the order by which the catalytic triad residues are positioned along amphiphilic $\beta$-strands influences both assembly structures and catalytic activity. A set of three $\beta$-sheet amphiphilic peptides, decorated with different orders of the catalytic triad amino acids, Glu, His and Ser along the strands were evaluated for their catalytic hydrolysis efficiency of $p$-nitrophenyl acetate ( $p N P A)$ substrate. Among the three peptides, Ac-Cys-Phe-Glu-Phe-Ser-Phe-His-PhePro- $\mathrm{NH}_{2}(\mathrm{ESH})$ achieved the greatest catalytic efficiency with a value of $0.19 \mathrm{M}^{-1} \mathrm{~s}^{-1}$, at peptide concentration of $250 \mu \mathrm{M}$. This study sheds light on an overlooked factor in designing catalytic amphiphilic assemblies whereby charged residues that make up the active sites, are in fact engaged in intermolecular stabilizing interactions that in turn may hamper their catalytic action.

Keywords: Self-assembly, biocatalysis, peptides, catalytic triad 


\section{Introduction}

Enzymes have always been a source of inspiration for their high catalytic efficiency and selectivity ${ }^{1-3}$. Enzymatic catalysis relies on a delicate balance between active residues positions and their conformational freedom within the protein framework ${ }^{4}$. In recent years various catalytic systems have been generated based on supramolecular structures of small molecules and peptides ${ }^{5-9}$. Peptides self-assemblies that may serve as templates for high density catalytic sites ${ }^{10-12}$ have thus far shown rather low catalytic efficiency and selectivity prompting further investigations into such systems. Various publications showed that mixtures of soluble amino acids do not exhibit catalytic activity ${ }^{11,13}$. Other studies emphasized peptides' catalytic activity dependence on specific supramolecular structures ${ }^{3,}$ ${ }^{14-25}$. Heller et al. discussed the effect of distance between active amino acids in the peptide on the catalytic activity ${ }^{26}$.

Numerous studies explored peptide systems that mimic serine proteases. Guler et al. developed peptide amphiphiles (PAs) carrying histidine groups that, after self-assembly into nanofibers, showed ester hydrolysis ${ }^{11}$. A mixture peptide amphiphiles each decorated by one of esterases' catalytic site residues, histidine, serine and aspartic acid, was found to hydrolyzed the commonly studied substrate, $p$-nitrophenyl acetate ( $p N P A)$, into $p$ nitrophenol $(p N P)$ with a catalytic efficiency of $126.62 \pm 14.58 \mathrm{M}^{-1} \mathrm{~s}^{-1}{ }^{13}$. Other studies explored esterase mimicking peptides that present all three catalytic site residues on amphiphilic $\beta$-sheet peptides ${ }^{16,23,26-29}$. These tend to form bilayer fibril assemblies that are held together by hydrogen bonds and hydrophobic interactions, while their hydrophilic residues including the catalytic amino acids, point toward the polar surroundings ${ }^{24}$. Murai et al. designed such a $\beta$-sheet peptide that acts both as a self-assembling template for calcium carbonate precipitation and as a catalyst for urea hydrolysis that provides carbonate ions to the precipitation reaction ${ }^{28}$. Zhang et al. attached a mixture of peptides SHELKLKLKL and WLKLKLKL to carbon nanotubes, which subsequently showed a catalytic efficiency of up to $0.62 \mathrm{M}^{-1} \mathrm{~s}^{-1}$ for the hydrolysis of $p N P A^{3}$. Li et al. showed that the dyad Ser-His in association with the C-termini may be considered the shortest catalytically active peptide ${ }^{30-34}$.

Here, we used a set of three amphiphilic $\beta$-sheet peptides with different combinations of the His, Ser and Glu catalytic triad, positioned on their hydrophilic face, to demonstrate the effect of the residues' order on both assembly and $p$ NPA hydrolysis ${ }^{35,36}$. These designed peptides share the common sequence Ac-Cys-Phe-X-Phe-Y-Phe-Z-Phe-Pro- $\mathrm{NH}_{2}$ with $\mathrm{X}, \mathrm{Y}$ and $\mathrm{Z}$ each representing one of the catalytic triad residues ( $\operatorname{Ser}=\mathrm{S}$, $\mathrm{His}=\mathrm{H}$, and $\mathrm{Glu}=\mathrm{E}$ ), denoted ESH, EHS and HES, according to the order of these amino acids along the strand (Figure 1). 
These peptides in $\beta$-sheet structures were previously shown by us to adsorb, to different extents, the organophosphate paraoxon, an irreversible inhibitor of acetylcholine esterase ${ }^{37-}$

39. In the study reported here we monitored peptides' catalytic activity on $p$ NPA hydrolysis in bulk, at different peptide concentrations. To investigate the structure-function relationship of the peptides we characterized their structure by Cryo-TEM and FTIR with and without $p N P A$ to elucidate the relation between peptides' structure and their function. We additionally investigated the peptide monolayer assembly at the air-water interface by grazing incidence X-ray diffraction (GIXD) to provide structural insights on peptide assembly within each layer composing the fibril bilayer ${ }^{40}$.

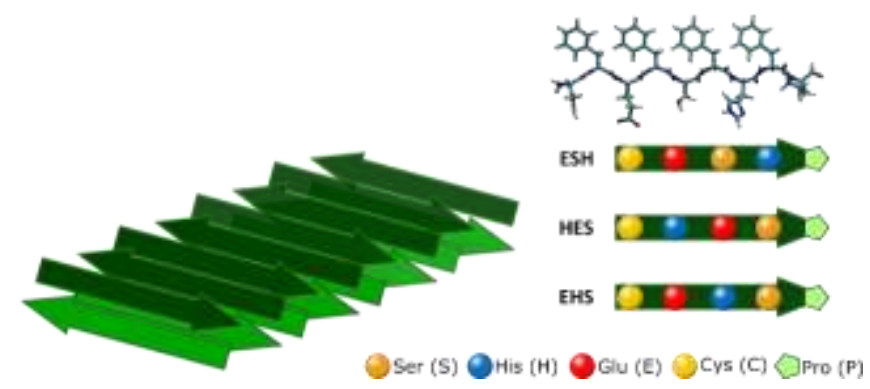

Figure 1. Left: Scheme of fibril assembly expected to be formed by amphiphilic $\beta$-sheet peptides in bulk. Arrows representation shows fibril structure in which each face of the fibril is composed of peptides packed in anti-parallel mode. The bilayer assembly enables shielding of the hydrophobic residues from solution. Right (from top down), the molecular structure (tube representation) of peptide ESH in $\beta$-pleated conformation, showing the opposite positioning of hydrophilic and hydrophobic residues. Peptides shown schematically as arrows along their hydrophilic face: Ac-CysPhe-Glu-Phe-Ser-Phe-His-Phe-Pro- $\mathrm{NH}_{2}$ (ESH), Ac-Cys-Phe-His-Phe-Glu-Phe-Ser-Phe-Pro-NH ${ }_{2}$ (HES) and Ac-Cys-Phe-Glu-Phe-His-Phe-Ser-Phe-Pro- $\mathrm{NH}_{2}$ (EHS).

\section{Materials and Methods}

Materials. Peptides were custom synthesized, then purified by high performance liquid chromatography to $95 \%$ and supplied as lyophilized powders by Genscript, NJ. Unless otherwise specified, all reagents were purchased from Sigma-Aldrich (Rehovot, Israel) and were of the highest available purity. Acetonitrile, $\mathrm{CH}_{3} \mathrm{CN}$, denoted $\mathrm{ACN}$, was purchased from Beith Dekel (Rehovot, Israel). All peptide solutions were prepared in deionized water/ACN $(50 \% \mathrm{v} / \mathrm{v})$ solution at $\mathrm{pH} 7$, unless otherwise mentioned. Chloroform $\left(\mathrm{CHCl}_{3}\right)$ was purchased from BioLab (Jerusalem, Israel). 
ATR-FTIR Infrared spectra of the lyophilized peptides were recorded by Nicolet 6700 FTIR (Thermo Fisher Scientific, Waltham, MA) instrument equipped with an MCT/A detector and a $\mathrm{KBr}$ beam splitter. In the case of peptides mixed with $p N P A$, liquid samples were frozen in liquid nitrogen two hours after mixing and then lyophilized prior to measurements. The lyophilized samples were uniformly distributed over the horizontally oriented germanium prism. The FTIR spectra were acquired from 64 scans at $4 \mathrm{~cm}^{-1}$ resolution and were adjusted for spectral distortion using atmospheric absorption corrections. All spectra were normalized by the $3300 \mathrm{~cm}^{-1}$ peak (see supplementary Figure S1) and the $1625 \mathrm{~cm}^{-1}$ peaks were then fitted to a Gaussian curve based on which their area was calculated (using Origin software).

Cryo Transmission Electron Microscopy (cryo-TEM) A $3 \mu \mathrm{L}$ droplet of peptide solution was deposited on a glow discharged TEM grid (300 mesh lacey Cu substrate grid; Ted Pella). The excess liquid was blotted with a filter paper. For cryogenic samples the specimen was rapidly plunged into liquid ethane precooled with liquid nitrogen in a controlled environment (Leica EM GP). Cryo-TEM imaging was taken by Talos F200C with a Schottky Field Emission Gun (FEG) emitter and a high voltage of $200 \mathrm{kV}$ with a Ceta 16M CCD Camera. Images were acquired for peptides at 250 and $500 \mu \mathrm{M}$ and for $250 \mu \mathrm{M}$ peptide with the addition of 500 $\mu \mathrm{M} p$ NPA. Peptides at $100 \mu \mathrm{M}$ showed no detectable structures by cryo-TEM. The brightness of images was enhanced using ImageJ software. The fibrils and aggregates diameter were measured by ImageJ based on 4 images and 20 items for each image, $n=80$ in total.

\section{Grazing incidence X-ray diffraction (GIXD) on peptide monolayer at the air-water interface}

The GIXD experiments described here were performed on the liquid surface diffractometer of SIRIUS beam line at SOLEIL synchrotron (Saint-Aubin, France) ${ }^{41}$. A peptide solution was prepared in $10 \mathrm{~mL} \mathrm{HFIP/chloroform} \mathrm{(5 \% ,v/v),} \mathrm{at} \mathrm{a} \mathrm{concentration} \mathrm{of} \mathrm{approximately} 0.35$ $\mathrm{mg} / \mathrm{ml}$. A few tens of microliters of the solution were spread on the surface of deionized water (DIW, $18.2 \mathrm{M} \Omega-\mathrm{cm}$ ) in a Langmuir trough. The amphiphilic peptides remain at the airwater interface, while the volatile organic solvent evaporates or, in the case of HFIP, dissolves in the water. The deposited Langmuir film was left to equilibrate for 1 hour prior to the initiation of the compression isotherm.

The peptide films were compressed to a surface pressure of $1 \mathrm{mN} / \mathrm{m}$. A monochromatic $\mathrm{x}$ ray beam $(1.24 \AA)$ was adjusted to strike the liquid surface at an incident angle $\theta=0.85 \theta_{c}\left(\theta_{c}\right.$ is the critical angle for total external reflection and is equal to $2.15 \mathrm{mrad}$ ), which maximizes surface sensitivity. The scattered intensity was collected using a 1D gas detector fixed on the 
2-axis detector arm of the beamline's diffractometer. A Soller slit collimator was positioned in front of the detector, leading to an in-plane wave vector resolution of $0.03 \mathrm{~nm}^{-1}$ in the recorded $\mathrm{q}_{\mathrm{xy}}$ range. Measurements were performed by scanning the horizontal component, $\mathrm{q}_{\mathrm{xy}}=4 \Pi \sin \alpha_{\mathrm{xy}} / \lambda$, of the scattering vector, where $2 \alpha_{\mathrm{xy}}$ is the angle between the incident and diffracted beam projected onto the horizontal plane. Each scan included 100 measuring points. Several measurements were acquired for each sample ( $n=5$ for HES and $n=7$ for ESH and EHS). The measured GIXD patterns and Bragg peaks given herein are representative out of a stable and reproducible situation.

The two-dimensional diffraction data are represented in two additional ways, as Bragg peaks that show $q_{z}$ integrated intensity as function of $q_{x y}$ and as their corresponding Bragg rods that are obtained by integrated intensity along $q_{x y}$ as function of $q_{z}$. Bragg peaks were fitted to a Lorentzian curve and Bragg rod with squared sinus cardinal. The $\mathrm{q}_{\mathrm{xy}}$ positions of the Bragg peaks yield the lattice spacings $d=2 \pi / q_{x y}$. The full-width at half-maximum $F W H M\left(q_{x y}\right)$ of the Bragg peaks yields the lateral 2D crystalline coherence length $L_{x y} \approx 0.9(2 \pi) /$ $\operatorname{FWHM}\left(q_{x y}\right)$. The width of the Bragg rod profile along $q_{z}$ gives an estimate of the thickness of the crystalline film: $h_{z} \approx 0.9(2 \pi) / F W H M\left(q_{z}\right)$.

Kinetic Assay From a stock solution of $1 \mathrm{mM} p$ NPA in DIW/ACN 50\% v/v, 20, 40, 60, 80 and $100 \mu \mathrm{L}$ were placed in different wells of a 96 well plate and complemented by the solvent to achieve $100,200,300,400$ and $500 \mu \mathrm{M}$ concentrations at a final volume of $100 \mu \mathrm{L}$. Finally, $100 \mu \mathrm{L}$ of peptide solution were added to each well to achieve a final peptide concentration of 100,250 or $500 \mu \mathrm{M}$. The absorption at $400 \mathrm{~nm}$ of para-nitrophenol ( $p N P)$, the product of pNPA hydrolysis, was measured every 20 seconds on a spectrophotometer (Multiskan GO, Thermo scientific, Waltham, MA). An extinction coefficient of $15,200 \mathrm{M}^{-1} \mathrm{~cm}^{-1}$ extracted from a calibration curve was used to determine the product concentration at $\mathrm{pH}$ value of 7 . The kinetic constants were calculated using Michaelis-Menten model ${ }^{21,42}$. Measurements were performed at $\mathrm{pH} 7$ and at $25^{\circ} \mathrm{C}$ in order to explore the ability to catalyze the reaction under mild conditions ${ }^{20}$. 


\section{Results}

\section{Screening peptides structures and their interactions with $p$ NPA}

GIXD patterns were acquired from peptide monolayers formed at the air-water interface. In such monolayer assemblies, $\beta$-sheet peptides point their hydrophobic amino acids to air and the hydrophilic ones to the water solution ${ }^{43}$. Hence, this system provides a good model for assaying preferred packing arrangements between $\beta$-strands that may also prevail in bulk solutions. The GIXD spectra of all the peptides at air-water interface were found to correspond to a monolayer with thickness of $17 \pm 1.2,18 \pm 1.3$ and $16 \pm 1 \AA$ for ESH, HES and EHS respectively, see Figure 2, right panel. In addition, a 4.8 Å spacing Bragg peak was shown for the three peptides at $q_{\mathrm{xy}}=1.31 \AA^{-1}$ (Figure 2, left panel), which corresponds to the distance between neighboring $\beta$-strands interacting through hydrogen bonds ${ }^{43}$. Peptide ESH yielded a Bragg peak with a FWHM of $0.292 \AA^{-1}$ that is appreciably larger than those of the two other peptides, HES and EHS, with a FWHM of 0.227 and $0.178 \AA^{-1}$ respectively, indicating that the latter peptides tend to form larger ordered domains than ESH. The fitted peak areas are $24.42,12.56$ and $19.43 \AA^{-1}$ for ESH, HES and EHS respectively, demonstrating that ESH forms more ordered structures (yet of smaller dimensions as noted by its Bragg peak FWHM) than the two other peptides. 
A)
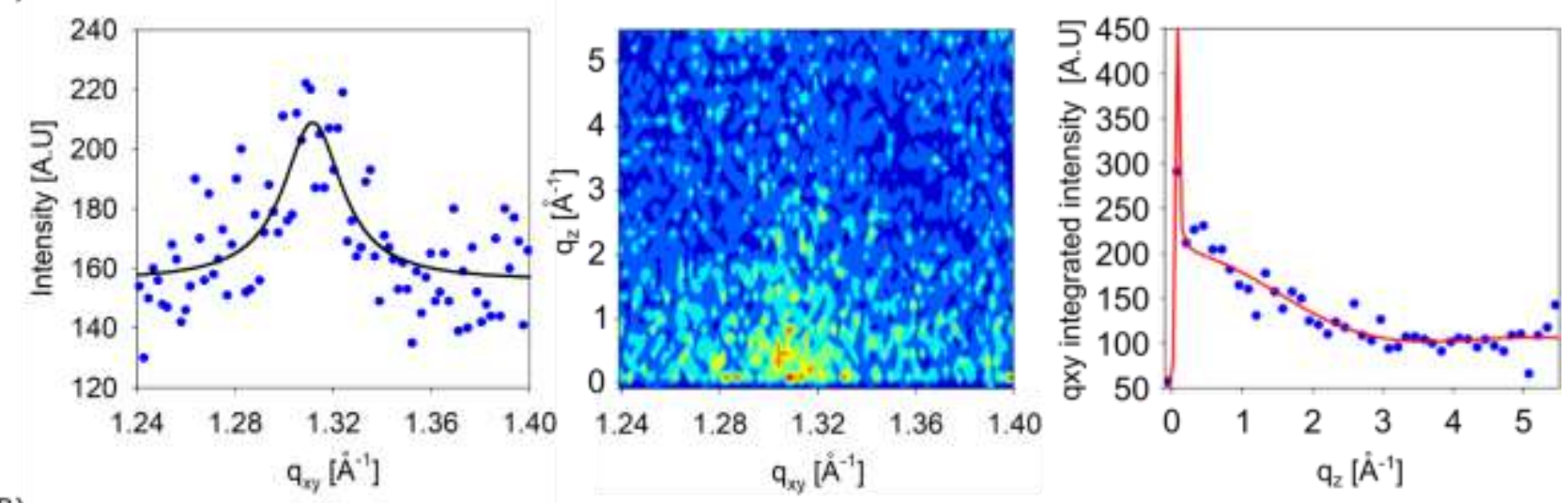

B)
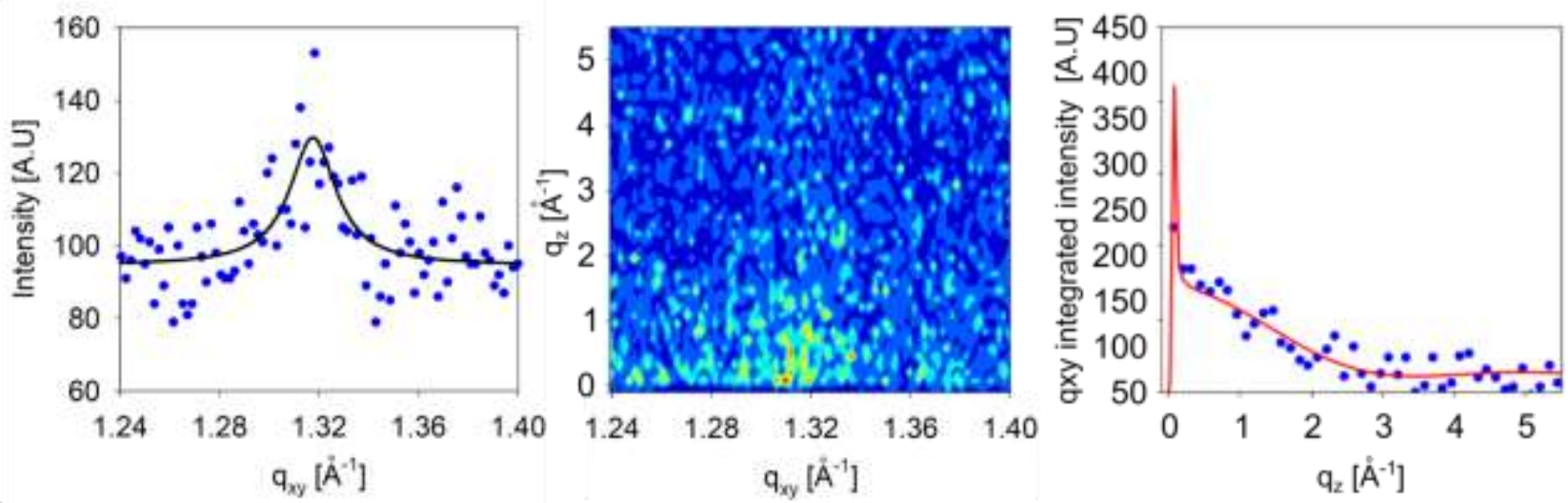

C)
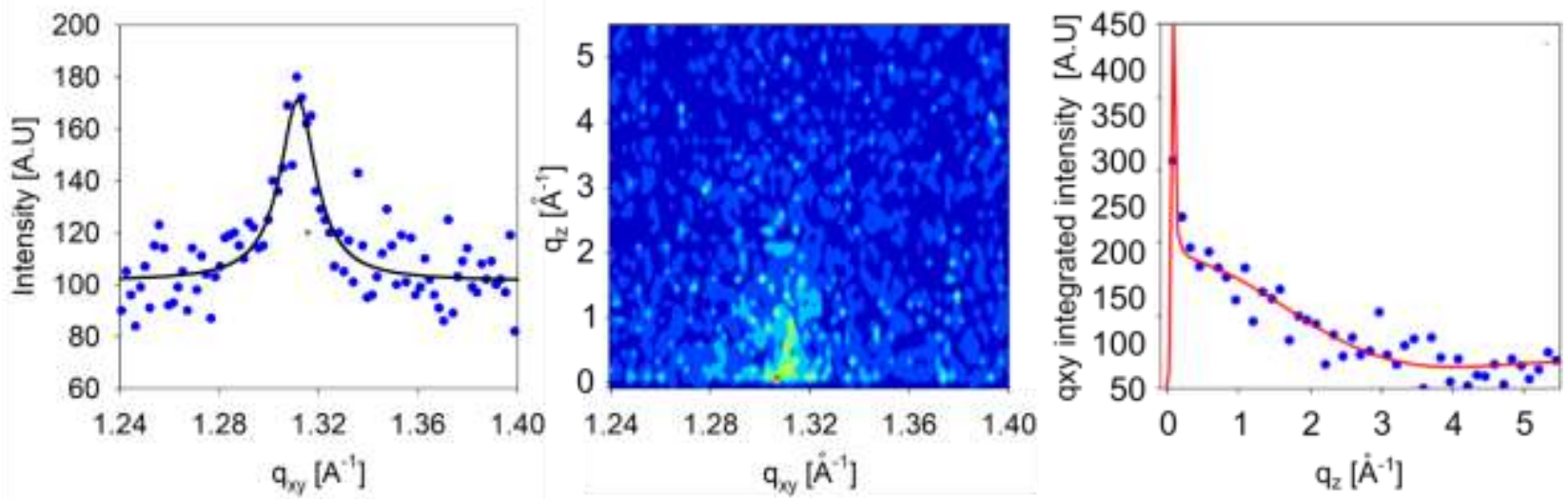

Figure 2. GIXD data of the peptide monolayers. Left panel: Bragg peaks showing integrated intensity along $\mathrm{q}_{\mathrm{z}}$ as function of $\mathrm{q}_{\mathrm{xy}}$, with measured data (blue circles) and Lorentzian fit (black lines). Center panel: the fully acquired two-dimensional GIXD contour plots. Right panel: Bragg rods showing the $q_{x y}$ integrated intensity (blue circles) as function of $q_{z}$ (red lines) A) ESH, B) HES, C) EHS

IR spectra of the lyophilized peptide solutions, at $250 \mu \mathrm{M}$ and their 1:1 molar mixture with pNPA (Figure 3) all exhibit the amide I absorption bands at $1624-1625 \mathrm{~cm}^{-1}$. These bands, together with the weak absorption band at $1670-1690 \mathrm{~cm}^{-1}$ provide evidence for antiparallel $\beta$-sheet structures ${ }^{43}, 44$. Note that amide I band of ESH peptide appears weaker than those of the two other peptides (calculated area of $74.2 \pm 1.4,82.0 \pm 1.3$ and $81.0 \pm 1.1$ for ESH, HES 
and EHS respectively) pointing to a weaker tendency to form $\beta$-sheet structures, in accordance with the FWHM of its GIXD Bragg peak that was wider than that of the two other peptides. The three peptides also show a peak at $1201 \mathrm{~cm}^{-1}$ attributed to Ser hydroxyls. The spectra of $p$ NPA and $p$ NP exhibits peaks at $\sim 1520$ and $1335 \mathrm{~cm}^{-1}$ corresponding to the aromatic bound nitro group. The spectrum of $p$ NPA also shows peaks at 1750 and $916 \mathrm{~cm}^{-1}$ attributed to $p N P A C=0$ and acetyl groups, respectively ${ }^{45,46}$. Interactions between peptides and $p$ NPA may in general be inferred from differences between the spectra of their mixtures and the spectra of each of the components. Only ESH peptide showed such differences in the $1750 \mathrm{~cm}^{-1}$ (see Figure 3) and $916 \mathrm{~cm}^{-1}$ peaks, which became hardly visible in the spectrum of ESH: $p N P A$ mixture, pointing to the hydrolysis of $p N P A$ into $p N P$, induced by this peptide. The interaction with $p$ NPA also affected the amide I peaks area. The peak area of ESH increased to $79.6 \pm 1.2$ indicating a higher tendency to form $\beta$-sheet structures in presence of $p$ NPA. In contrast, the peak area of HES was decreased to $69.3 \pm 1.1$ and the peak area of EHS remained unchanged, $81.5 \pm 1.3$.

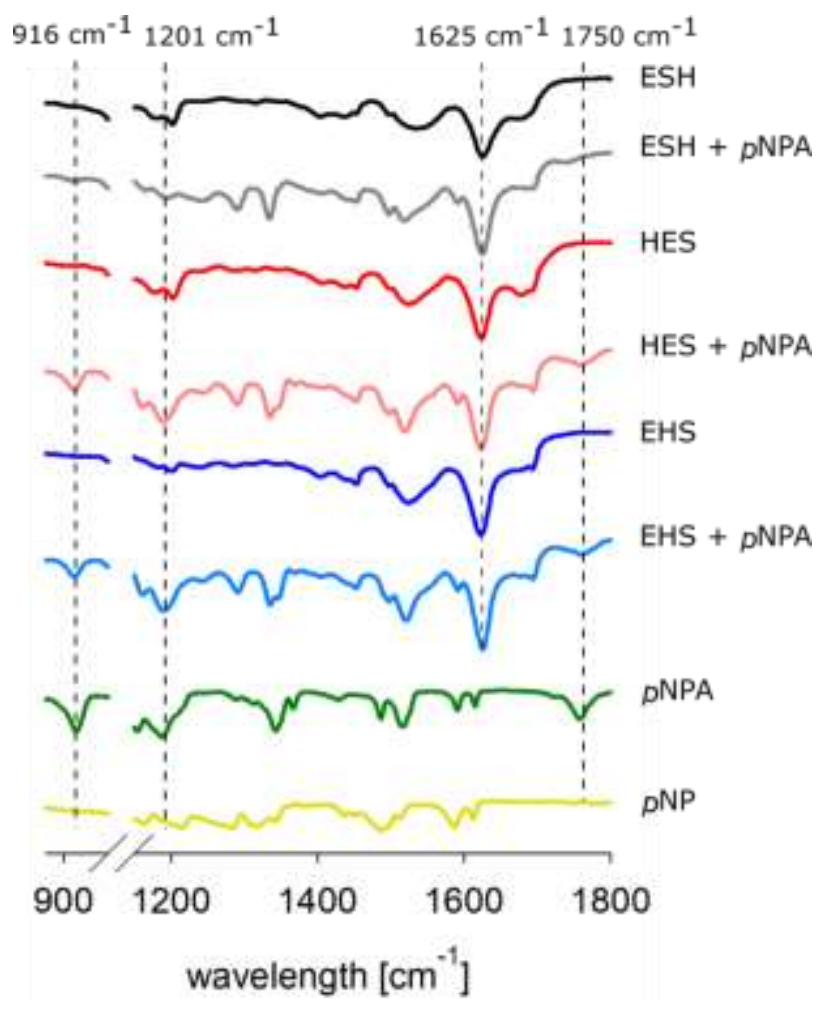

Figure 3. ATR-FTIR transmittance spectra of lyophilized solutions, of peptides $(250 \mu \mathrm{M})$ and their equimolar mixtures with $p$ NPA. Spectra of $p N P A$ and $p N P$ are provided for comparison.

Cryo-TEM images were acquired with peptides at $250 \mu \mathrm{M}$ (Figure $4 \mathrm{~A}-\mathrm{C}$ and supplementary Figure S2-4), their mixtures with pNPA (Figure 4 D-F) and peptides only at $500 \mu \mathrm{M}$ (Figure 4 G-I), to demonstrate the peptides' assembly forms and how their structure is influenced by 
the presence of the substrate. ESH exhibited elongated aggregates at $250 \mu \mathrm{M}$ (Figure $4 \mathrm{~A}$ and inset) and short fibrils at $500 \mu \mathrm{M}$ (Figure 4G, resembling a previously reported image of this peptide ${ }^{37}$ ). In the presence of $250 \mu \mathrm{M}$ pNPA ESH forms long fibrils (of a few hundred $n m$ and with a thickness of $8.0 \pm 1.9 \mathrm{~nm}$ ) with apparition of round structures of $45.0 \pm 11.4 \mathrm{~nm}$ diameter, pointing to interactions with the small molecule. HES and EHS at $250 \mu \mathrm{M}$ (Figure 4 B-C) showed fairly similar fibril assemblies with thickness of $8.9 \pm 2.7 \mathrm{~nm}$ and $9.9 \pm 3.2 \mathrm{~nm}$, respectively, many of which were twisted (see insets), whereas EHS also displayed round shaped aggregates with diameter of $34.0 \pm 9.6 \mathrm{~nm}$. EHS mixed at $250 \mu \mathrm{M}$ with $p$ NPA exhibited more of the round shaped domains with similar diameter of $40.3 \pm 9.0 \mathrm{~nm}$ (Figure $4 \mathrm{~F}$ ) whereas HES at this concentration appeared not to be influenced by $p$ NPA (Figure $4 \mathrm{E}$ ). Both HES and EHS at $500 \mu \mathrm{M}$ showed extensive formation of fibrils pointing to potentially similar intermolecular interactions that modulate the overall shape of the fibrils. Furthermore, these results echo the differences in GIXD Bragg peaks FWHM and amide I calculated area, between ESH and the two peptides HES and EHS with the latter two showing a larger tendency to form $\beta$-sheet assemblies. 

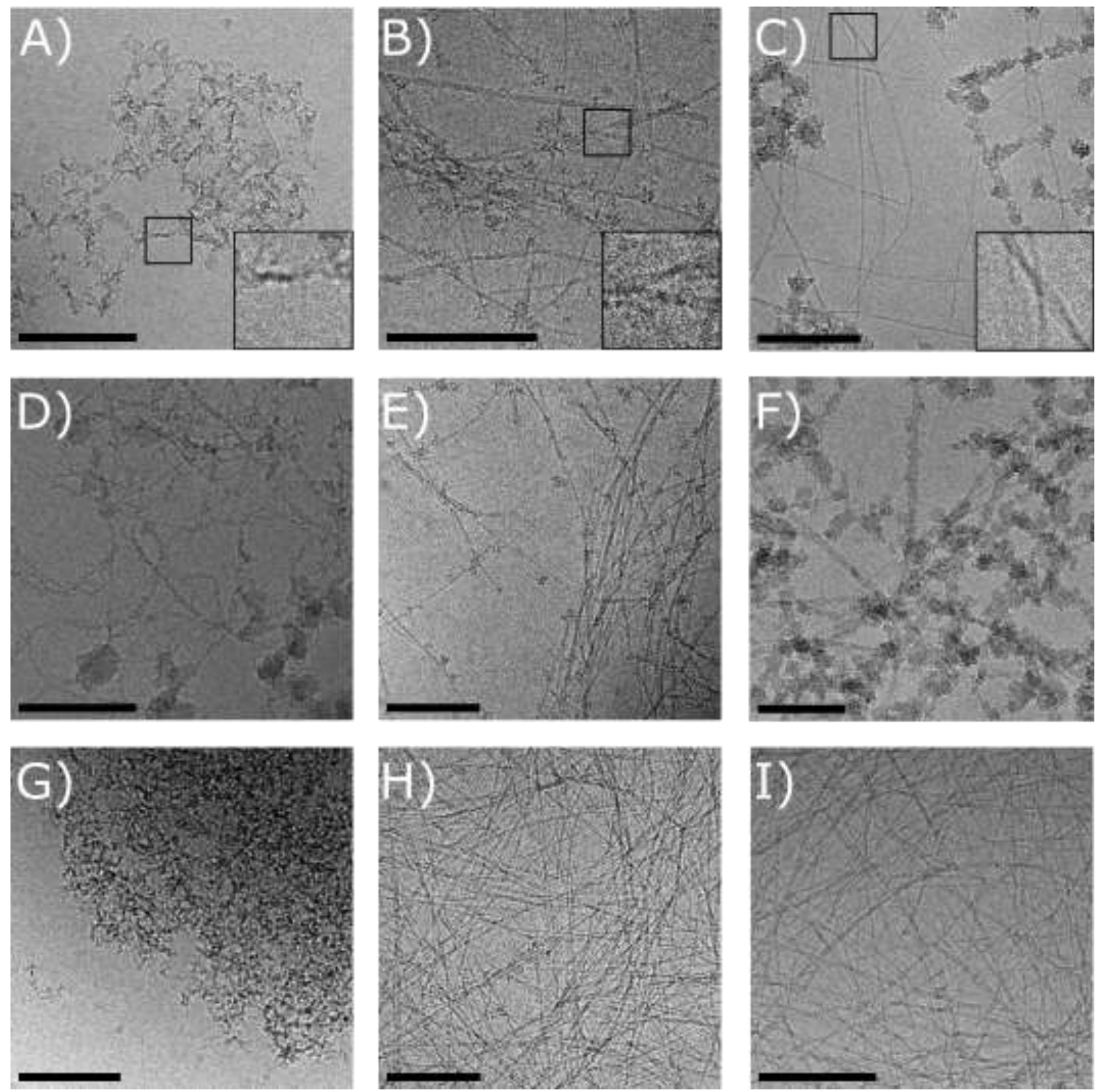

Figure 4. Cryo-TEM images of ESH, HES and EHS, respectively left, center and right columns. First row at $250 \mu \mathrm{M}$, second row at $250 \mu \mathrm{M}$ with the addition of $500 \mu \mathrm{M} p \mathrm{NPA}$ and third row at $500 \mu \mathrm{M}$. Scale bars $=200 \mathrm{~nm}$. (The brightness was enhanced in all images using image J)

\section{Catalytic Activity}

Spectroscopic measurements were applied to monitor the hydrolysis of $p$ NPA into $p$ NP by the peptides at three different concentrations, at 100, 250 and $500 \mu \mathrm{M}$, in order to assess the impact of their assembly states (as detected in TEM images) on catalysis. MichaelisMenten enzyme catalysis model ${ }^{21,42}$ was used to fit the data and calculate catalytic activity and catalytic efficiency values (Table 1 and Figure 5). Among the three peptides, ESH showed 
the greatest catalytic efficiency at the three concentrations and the highest value, $0.19 \mathrm{M}^{-1} \mathrm{~s}^{-}$ ${ }^{1}$, at $250 \mu \mathrm{M}$. Interestingly, according to GIXD and TEM images this peptide showed the weakest tendency for fibril formation; hence the catalysis appears to be attributed to only partially developed fibrillary aggregates (Figure $4 \mathrm{D}$ ). The decrease in the catalytic activity of $\mathrm{ESH}$, to $9.75^{*} 10^{-2} \mathrm{M}^{-1} \mathrm{~s}^{-1}$, at $500 \mu \mathrm{M}$, may be attributed to denser peptide structures (Figure 4 G) with less accessible catalytic sites. HES, which showed quite similar fibrillar structures at all concentrations (Figures 4 B, E and H), also exhibited similar catalytic activity at 100 and $250 \mu \mathrm{M}$, whereas at $500 \mu \mathrm{M}$ its catalytic activity was too noisy to extrapolate its kinetic constants. EHS showed similar catalytic activity at 100 and $500 \mu \mathrm{M}$ and it could be speculated that the round shape aggregates observed by cryo-TEM at $250 \mu \mathrm{M}$ (Figures $4 \mathrm{C}$ and F) hampered its catalytic activity.

Table 1. Catalytic activity of the designed peptides at different concentrations (number of repetitions: $n=4)$. The data represent mean \pm standard deviation. The catalytic constants of the peptide HES at concentration of $500 \mu \mathrm{M}$ could not be calculated due to highly noisy measurements of the absorbance at $400 \mathrm{~nm}$ over time.

\begin{tabular}{|c|c|c|c|c|}
\hline $\begin{array}{l}\text { peptide } \\
\text { concentr }\end{array}$ & {$[\mu \mathrm{M}]$} & 100 & 250 & 500 \\
\hline \multicolumn{5}{|l|}{ ESH } \\
\hline kcat & {$\left[\mathrm{s}^{-1}\right]$} & $2.95 \pm 0.47 * 10^{-4}$ & $8.36 \pm 0.89 * 10^{-5}$ & $1.6 \pm 0.33 * 10^{-4}$ \\
\hline $\mathrm{Km}$ & {$[\mathrm{M}]$} & $0.67 \pm 1.02 * 10^{-3}$ & $4.36 \pm 0.47 * 10^{-4}$ & $1.62 \pm 0.35 * 10^{-3}$ \\
\hline$\varepsilon$ & {$\left[\mathrm{M}^{-1} \mathrm{~s}^{-1}\right]$} & $5.01 \pm 1.17 * 10^{-2}$ & $0.19 \pm 0.03$ & $9.75 \pm 2.89 * 10^{-2}$ \\
\hline \multicolumn{5}{|l|}{ HES } \\
\hline kcat & {$\left[\mathrm{s}^{-1}\right]$} & $6.81 \pm 1.36 * 10^{-5}$ & $1.37 \pm 1.07 * 10^{-4}$ & results cannot be \\
\hline $\mathrm{Km}$ & {$[\mathrm{M}]$} & $8.97 \pm 2.43 * 10^{-4}$ & $2.69 \pm 2.1 * 10^{-3}$ & $\begin{array}{l}\text { analyzed due to highly } \\
\text { noisy measurements }\end{array}$ \\
\hline$\varepsilon$ & {$\left[\mathrm{M}^{-1} \mathrm{~s}^{-1}\right]$} & $7.59 \pm 2.56 * 10^{-2}$ & $5.08 \pm 5.69 * 10^{-2}$ & \\
\hline \multicolumn{5}{|l|}{ EHS } \\
\hline kcat & {$\left[\mathrm{s}^{-1}\right]$} & $1.78 \pm 0.18 * 10^{-5}$ & $8.28 \pm 2.00 * 10^{-6}$ & $4.02 \pm 1.2 * 10^{-5}$ \\
\hline $\mathrm{Km}$ & {$[\mathrm{M}]$} & $6.78 \pm 0.77 * 10^{-4}$ & $8.06 \pm 2.04 * 10^{-4}$ & $9.84 \pm 3.07 * 10^{-4}$ \\
\hline$\varepsilon$ & {$\left[\mathrm{M}^{-1} \mathrm{~s}^{-1}\right]$} & $2.63 \pm 0.4 * 10^{-2}$ & $1.03 \pm 0.36 * 10^{-2}$ & $4.08 \pm 1.76 * 10^{-2}$ \\
\hline
\end{tabular}




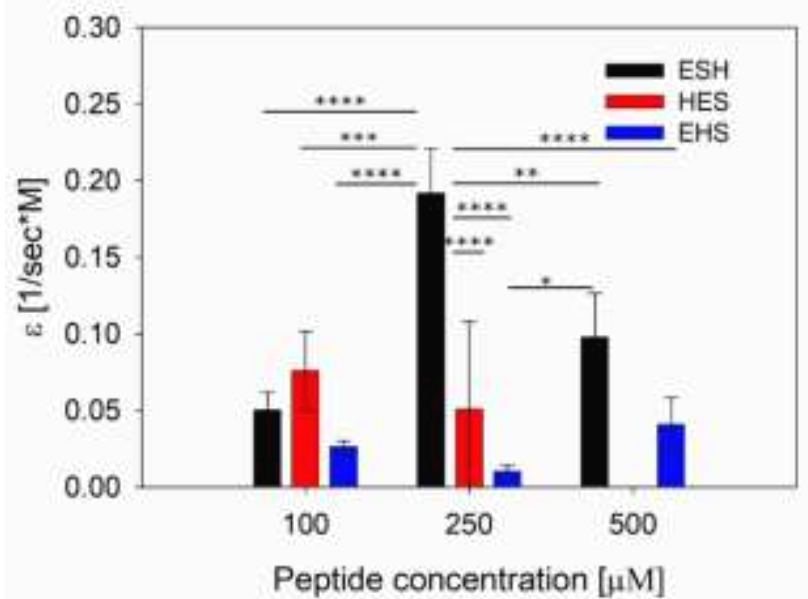

Figure 5. Catalytic efficiency $\left(\mathrm{k}_{\mathrm{cat}} / \mathrm{K}_{\mathrm{m}}\right)$ of the three peptides at different concentrations. Tukey's multiple comparisons test was used to calculate $p$-values. Statistically significant differences were marked as follows: ${ }^{*} p<0.05, * * p<0.01, * * * p<0.001, * * * * p<0.0001, n=4$; error bars represent the standard deviation.

\section{Discussion}

Peptides were designed to present different orders of the catalytic amino acids on their hydrophilic faces. Based on GIXD and IR measurements the three peptides form antiparallel $\beta$-sheet structures. HES and EHS were found to form larger $\beta$-sheet monolayer domains and more developed fibril structures according to TEM compared to ESH, yet the latter showed higher extent (indicated by Bragg peak area) of smaller ordered domains (according to Bragg peak's FWHM). We propose that the major differences between ESH and the two other peptides stem from differing cross-strand electrostatic interactions. Figure 6 shows the three peptides in antiparallel arrangement, juxtaposed so to maximize potential inter-strand electrostatic interactions. For HES and EHS peptides this inter-strand packing should include an offset between neighboring anti-parallel strands, in order to position opposite charges in face-to-face, whereas for ESH no such offset is needed to satisfy balanced electrostatics at pH 7. In this proposed packing, HES and EHS peptides position their Glu residues in crossstrand pairs with His, a motif that is likely to repeat along the fibril arrangement. ESH peptides that pack with no offset between cross-strands also enable interstrand electrostatic interactions between these two residues. Furthermore, the two models generate different lattice arrangements of the charged residues, which in turn should influence their stability and catalytic activity. We have previously reported electrostatic complementary interactions dominating amphiphilic $\beta$-sheet peptide assembly structures ${ }^{47,48}$. We note that fibrillar structures of $\beta$-sheets may be quite rigid, being held by two hydrogen bonds per amino acid and additional intermolecular hydrophobic and electrostatic interactions. It is possible that 
these stabilizing interactions hamper the flexibility needed to successfully accomplish catalytic activity ${ }^{4}$. Indeed, the well-defined $\beta$-sheet structures of EHS and HES peptides within the extended fibrils observed by cryo-TEM also showed low catalytic activity. In contrast, the less developed fibrils of ESH, particularly at concentration of $250 \mu \mathrm{M}$, apparently provide balance between order and dynamics required to support the kinetic activity (Table 1$)^{14,49,50}$, as a less ordered structure may authorize more dynamic movements ${ }^{51}$. An additional evidence for the flexibility of ESH may be inferred from the change in its overall structure in the presence of $p$ NPA, according to FTIR (Figure 3 ) and cryoTEM images (Figures 4 A and D and supplementary Figure S2). In a previous study we also found that among these three peptides, that were tested at concentrations 50, 100250 and $400 \mu \mathrm{M}$, for adsorption of the organophosphate paraoxon, ESH performed best at the fairly low concentration of $100 \mu \mathrm{M}^{37}$. It is interesting to note that the internal dynamics of fibrils was also pointed out by others to be a pivotal factor in catalytic activity ${ }^{52}$.

As His residue is essential to the catalytic activity through its ability to activate a Ser residue ${ }^{53}$, the mutual arrangement of these two amino acids in the assemblies may also influence the catalytic activity. Thus, the ESH superiority over EHS and HES peptides can be analyzed with respect to Ser neighbors in the peptide assembly, based on the schematic arrangement shown in Figure 6. The higher catalytic activity of ESH may be associated with its Ser residues being surrounded by three His residues, whereas in HES and EHS this amino acid is surrounded by only two and one His residues, respectively.

Our findings are in qualitative agreement with the results of Friedmann et al. ${ }^{16}$, who examined the hydrolysis rate of $p$ NPA for a large number of peptides of the form AcYVXVXVXV-CONH ${ }_{2}(X=A / D / H / S)$. They reported that among all the tested peptides that hold a catalytic triad, the ones presenting the HSD sequence, very similar to the catalytic triad in ESH herein, exhibited the highest hydrolysis rate, about 1.5 times higher than the spontaneous hydrolysis rate of $p$ NPA.
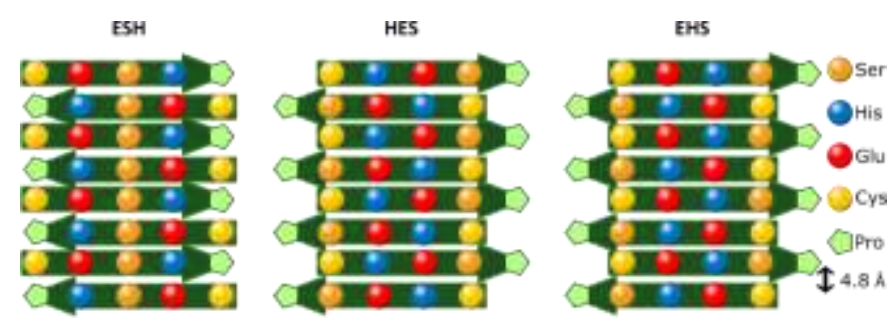

Figure 6. Packing arrangement of the three peptides viewed along the hydrophilic face of the strands, showing eight monomers in anti-parallel $\beta$-sheet: ESH (left), HES (center) and EHS (right). This scheme 
demonstrates how the offset in neighboring strands can bring oppositely charged residues into close proximity.

\section{Conclusions}

The unique $\beta$-sheet peptide system presented herein highlights the influence of the catalytic amino acids order on assembly forms and catalytic activity. The results stress the possibility that highly ordered structures may not necessarily improve catalytic activity. Furthermore, in order to enhance amphiphilic $\beta$-sheet peptide catalytic activity, it is necessary to optimize amino acids order along the peptide backbone with respect to intermolecular interactions, especially electrostatic ones and nearest neighbor residues. Peptide concentration can also be harnessed to find a balance between structural order and structural dynamics in $\beta$-sheet structures.

Authors contribution

The manuscript was written through contributions of all authors. All authors have given approval to the final version of the manuscript.

\section{Conflicts of interest}

There are no conflicts to declare.

\section{Acknowledgements}

We would like to thank SOLEIL for the provision of beamtime that allowed us to obtain the GIXD measurements. We would also like to thank Dr. Einat Nativ-Roth for helping us to operate the Cryo Transmission Electron Microscopy images. 


\section{References}

1. I. V. Korendovych and W. F. DeGrado, Curr. Opin. Struct. Biol., 2014, 27, 113-121.

2. C. G. Pappas, I. R. Sasselli and R. V. Ulijn, Angewandte Chemie-International Edition, 2015, 54, 8119-8123.

3. Q. Zhang, X. X. He, A. L. Han, Q. X. Tu, G. Z. Fang, J. F. Liu, S. Wang and H. B. Li, Nanoscale, 2016, 8, 16851-16856.

4. T. Takahashi, M. Cheung, T. Butterweck, S. Schankvveiler and M. J. Heller, Catalysis Communications, 2015, 59, 206-210.

5. K. S. Broo, L. Brive, P. Ahlberg and L. Baltzer, Journal of the American Chemical Society, 1997, 119, 11362-11372.

6. M. C. Kim and S. Y. Lee, Chemistry-a European Journal, 2014, 20, 17019-17024.

7. M. Tena-Solsona, J. Nanda, S. Diaz-Oltra, A. Chotera, G. Ashkenasy and B. Escuder, Chemistry-a European Journal, 2016, 22, 6687-6694.

8. M. J. Webber, E. A. Appel, E. W. Meijer and R. Langer, Nature Materials, 2016, 15, 13-26.

9. Z. Lengyel, C. M. Rufo, Y. S. Moroz, O. V. Makhlynets and I. V. Korendovych, Acs Catalysis, 2018, 8, 59-62.

10. T. O. Omosun, M. C. Hsieh, W. S. Childers, D. Das, A. K. Mehta, N. R. Anthony, T. Pan, M. A. Grover, K. M. Berland and D. G. Lynn, Nature Chemistry, 2017, 9, 805-809.

11. M. O. Guler and S. I. Stupp, Journal of the American Chemical Society, 2007, 129, 12082-+.

12. P. Krattiger, R. Kovasy, J. D. Revell, S. Ivan and H. Wennemers, Organic Letters, 2005, 7, 1101-1103.

13. G. Gulseren, M. A. Khalily, A. B. Tekinay and M. O. Guler, Journal of Materials Chemistry B, 2016, 4, 4605-4611.

14. Y. S. Bai, A. Chotera, O. Taran, C. Liang, G. Ashkenasy and D. G. Lynn, Chemical Society Reviews, 2018, 47, 5444-5456.

15. M. S. Ekiz, G. Cinar, M. A. Khalily and M. O. Guler, Nanotechnology, 2016, 27.

16. M. P. Friedmann, V. Torbeev, V. Zelenay, A. Sobol, J. Greenwald and R. Riek, Plos One, 2015, 10.

17. A. M. Garcia, M. Kurbasic, S. Kralj, M. Melchionna and S. Marchesan, Chemical Communications, 2017, 53, 8110-8113.

18. B. Lewandowski and H. Wennemers, Current Opinion in Chemical Biology, 2014, 22, 40-46.

19. Y. Maeda, J. Fang, Y. Ikezoe, D. H. Pike, V. Nanda and H. Matsui, Plos One, 2016, 11.

20. Y. Maeda, O. V. Makhlynets, H. Matsui and I. V. Korendovych, in Annual Review of Biomedical Engineering, Vol 18, ed. M. L. Yarmush, 2016, vol. 18, pp. 311-328.

21. C. M. Rufo, Y. S. Moroz, O. V. Moroz, J. Stohr, T. A. Smith, X. Z. Hu, W. F. DeGrado and I. V. Korendovych, Nature Chemistry, 2014, 6, 303-309.

22. N. Singh, M. Kumar, J. F. Miravet, R. V. Ulijn and B. Escuder, Chemistry-a European Journal, 2017, 23, 981-993.

23. Y. M. Wong, H. Masunaga, J. A. Chuah, K. Sudesh and K. Numata, Biomacromolecules, 2016, 17, 3375-3385.

24. O. Zozulia, M. A. Dolan and I. V. Korendovych, Chemical Society Reviews, 2018, 47, 3621-3639. 
25. C. Q. Zhang, R. Shafi, A. Lampel, D. MacPherson, C. G. Pappas, V. Narang, T. Wang, C. Maldarelli and R. V. Ulijn, Angewandte Chemie-International Edition, 2017, 56, 14511-14515.

26. T. Takahashi, B. C. V. Ngo, L. Y. Xiao, G. Arya and M. J. Heller, Journal of Biomolecular Structure \& Dynamics, 2016, 34, 463-474.

27. Y. Fukushima, Bulletin of the Chemical Society of Japan, 1996, 69, 2269-2274.

28. K. Murai, M. Higuchi, T. Kinoshita, K. Nagata and K. Kato, Chemical Communications, 2013, 49, 9947-9949.

29. K. Murai, T. Kinoshita, K. Nagata and M. Higuchi, Langmuir, 2016, 32, 9351-9359.

30. M. Gorlero, R. Wieczorek, K. Adamala, A. Giorgi, M. E. Schinina, P. Stano and P. L. Luisi, Febs Letters, 2009, 583, 153-156.

31. Y. S. Li, Y. F. Zhao, S. Hatfield, R. Wan, Q. Zhu, X. H. Li, M. McMills, Y. Ma, J. Li, K. L. Brown, C. He, F. Liu and X. Z. Chen, Bioorganic \& Medicinal Chemistry, 2000, 8, 26752680.

32. Y. Ma, X. Chen, M. Sun, R. Wan, C. Zhu, Y. Li and Y. Zhao, Amino Acids, 2008, 35, 251256.

33. M. J. MacDonald, L. D. Lavis, D. Hilvert and S. H. Gellman, Organic Letters, 2016, 18, 3518-3521.

34. R. Wieczorek, K. Adamala, T. Gasperi, F. Polticelli and P. Stano, Life-Basel, 2017, 7.

35. T. Q. Luong, N. Erwin, M. Neumann, A. Schmidt, C. Loos, V. Schmidt, M. Fandrich and R. Winter, Angewandte Chemie-International Edition, 2016, 55, 12412-12416.

36. O. Monasterio, E. Nova and R. Diaz-Espinoza, Biochemical and Biophysical Research Communications, 2017, 482, 1194-1200.

37. A. B. Leshem, S. Isaacs, S. K. Srivastava, I. Abdulhalim, A. Kushmaro and H. Rapaport, Journal of Colloid and Interface Science, 2018, 530, 328-337.

38. Y. Liebes-Peer, H. Rapaport and N. Ashkenasy, Acs Nano, 2014, 8, 6822-6832.

39. K. Yaakobi, Y. Liebes-Peer, A. Kushmaro and H. Rapaport, Langmuir, 2013, 29, 68406848.

40. S. Segman-Magidovich, H. Grisaru, T. Gitli, Y. Levi-Kalisman and H. Rapaport, Advanced Materials, 2008, 20, 2156-+.

41. P. Fontaine, G. Ciatto, N. Aubert and M. Goldmann, Science of Advanced Materials, 2014, 6, 2312-2316.

42. A. R. Tzafriri, Bulletin of Mathematical Biology, 2003, 65, 1111-1129.

43. H. Rapaport, K. Kjaer, T. R. Jensen, L. Leiserowitz and D. A. Tirrell, Journal of the American Chemical Society, 2000, 122, 12523-12529.

44. S. Krimm and J. Bandekar, Advances in Protein Chemistry, 1986, 38, 181-364.

45. P. Damman and J. Point, Macromolecules, 1994, 27, 3919-3925.

46. D. Lin-Vien, N. B. Colthup, W. G. Fateley and J. G. Grasselli, The handbook of infrared and Raman characteristic frequencies of organic molecules, Elsevier, 1991.

47. S. Segman-Magidovich, M. R. Lee, V. Vaiser, B. Struth, S. H. Gellman and H. Rapaport, Chemistry-a European Journal, 2011, 17, 14857-14866.

48. R. Sneer, M. J. Weygand, K. Kjaer, D. A. Tirrell and H. Rapaport, Chemphyschem, 2004, 5, 747-750.

49. Z. P. Huang, S. W. Guan, Y. G. Wang, G. N. Shi, L. N. Cao, Y. Z. Gao, Z. Y. Dong, J. Y. Xu, Q. Luo and J. Q. Liu, Journal of Materials Chemistry B, 2013, 1, 2297-2304.

50. G. C. Li, A. K. Srivastava, J. Kim, S. S. Taylor and G. Veglia, Biochemistry, 2015, 54, 4042-4049.

51. J. H. Ortony, C. J. Newcomb, J. B. Matson, L. C. Palmer, P. E. Doan, B. M. Hoffman and S. I. Stupp, Nature Materials, 2014, 13, 812-816. 
52. R. H. Song, X. L. Wu, B. Xue, Y. Q. Yang, W. M. Huang, G. X. Zeng, J. Wang, W. F. Li, Y. Cao, W. Wang, J. X. Lu and H. Dong, Journal of the American Chemical Society, 2019, 141, 223-231.

53. P. Masson and D. Rochu, Acta Naturae, 2009, 1, 68-78. 